\title{
Sifat Fisik Buah Kakao (Theobroma cacao .L) Terhadap Pengaplikasian Teknik Sambung Samping
}

\author{
Nurhaya Kusmiah ${ }^{1 *}$, Fitrianti' ${ }^{2}$, Muh. Arman Yamin ${ }^{3}$ \\ ${ }^{1,3}$ Program Studi Agribisnis Universitas Al Asyariah Mandar \\ ${ }^{2}$ Program Studi Agroteknologi Universitas Al Asyariah Mandar \\ *Email : nurhayakusmiah@gmail.com
}

\begin{abstract}
Abstrak
Kakao merupakan komoditas pertanian yang berperan dalam peningkatan pendapatan Negara, namun permasalahan yang saat ini dihadapi yaitu rendahnya kualitas fisik dari buah kakao, hal ini dipicu dari banyaknya tanaman kakao yang saat ini tidak lagi produktif, sehingga diperlukan pengaplikasian teknik sambung samping dalam hal meregenerasikan kembali tanaman kakao Indonesia Khususnya Polewali Mandar. Penelitian ini bertujuan untuk mengatahui sejauh mana pengaplikasian teknik sambung samping pada tanaman kakao dapat meningkatkan kualitas tanaman kakao, dilihat dari ukuran panjang, berat dan diameter buah kakao. Metode yang digunakan dalam penelitian ini yaitu Rancangan Acak Kelompok, dengan 3 perlakuan penggunaan entris yang berbeda, diantaranya, entris S1 (Sulawesi 1), entris S2 (Sulawesi 2), dan entris MCC (45), serta Lokal (Tanpa Pengaplikasian Teknik Sambung Samping) sebagai sampel kontrol dengan parameter yang diuji yaitu Berat buah, panjang buah dan diameter buah Kakao. Analisis data dilakukan dengan menggunakan SPSS ver. 21 menggunakan analisis Anova. Hasil Penelitian menunjukkan bahwa berat buah kakao dengan teknik sambung samping menggunakan entries MCC paling tinggi dengan nilai rata-rata 745 gr, sedangkan berat paling rendah yaitu S1 dengan nilai 488 gr. Untuk pengujian panjang buah, hasil menunjukkan bahwa entries MCC paling tinggi dengan nilai 21,2 cm, dan terendah yaitu entries S1 dengan nilai $20 \mathrm{~cm}$, sedangkan parameter diameter buah diperoleh hasil tertinggi pada MCC dengan nilai 9,2 cm dan terendah yaitu S1 dengan nilai $8 \mathrm{~cm}$. Dari perbandingan parameter uji dengan perlakuan dan sampel kontrol, dapat ditarik kesimpulan bahwa Pengaplikasian Teknik Sambung Samping pada Tanaman Kakao dengan menggunan entris yang berbeda, berpengaruh nyata terhadap Berat, Panjang dan Diameter Buah Kakao.
\end{abstract}

Kata Kunci : entris, teknik sambung samping, buah kakao, kulitas fisik

\section{Pendahuluan}

Kakao merupakan salah satu komoditas perkebunan yang saat ini banyank dibudidayakan oleh masyarakat, dikarenakan tanaman ini dapat tumbuh baik pada iklim dan tanah di beberapa daerah di Indonesia, sehingga cukup mudah untuk memproduksi buah kakao bagi masyarakat Indinesia, oleh sebab itu kakao menjadi salah satu komoditas unggulan bagi sektror perkebunan Indonesia karena dapat dipasarkan di Perdagangan Internasional, dan juga Kakao ini sangat berperan dalam mendorong pengemabngan agroindistri di Indonesia (Puspita, Hidayat et al. 2015).

Produksi Kakao di Indonesia mulai dari tahun 1995, terus mengalami perkembangan, dimana peningkatan produksi Kakao Indonesia terus terjadi, seperti pada data Direkotorat Jenderal Perkebunan Indonesia, produksi kakao mencapai 304.866 ton pada tahun 1995, hingga tahun 2015 terus mengalami peningkatan mencapai 593.331 ton, dan produksi terbesar pada tahun 2010 sebesar 837.918 ton (Perkebunan, 2016).

Berdasarkan pada data yang dikeluarkan oleh International Cocoa Organization, menunjukkan bahwa harga jual dunia dari biji kakao mengalami fluktuasi, hingga pada tahun 2015 harga kakao sebesar USD 3.134,64 per ton (Organization, 2017).

Harga kakao yang berfluktuasi ini dipengaruhi oleh mutu biji yang saat ini kurang diperhatikan oleh petani, rendahnya mutu karena, kemampuan petani yang masih terbilang kurang dalam mengaplikasikan teknologi pada budidaya kakao di perkebunan, dan umumnya tanaman kakao dari petani merupakan tanaman yang sudah berumur hingga puluhan tahun, sehingga tidak begitu berproduksi, sehingga permasalahan ini cukup kompleks, hal ini bisa menyebabkan harga kakao terus menurun karena jumlah dan ukuran biji juga menurun, sementara biaya perawatan untuk budidaya kakao terus meningkat.

Standar mutu dari biji kakao ditentukan sebagai tolak ukur untuk pengawasan pengendalian mutu. Setiap bagian biji kakao yang akan diekspor harus memenuhi persyaratan standar mutu tersebut yang diawasi oleh lembaga pengawasan terkait yang ditunjuk.

Pengembangan kakao memang tidak terlepas dari perannya sebagai salah satu komoditas perkebunan yang menjadi fokus pengembangan untuk tujuan ekspor. Pengembangan kakao merupakan upaya yang dilaksanakan untuk mengembangkan dan meningkatkan mutu tanaman 
ekspor dalam rangka mempertahankan pangsa pasar internasional yang sudah ada serta penetrasi pasar yang baru. Sesuai dengan tujuan pemerintah yang menjadikan kakao sebagai komoditas ekspor andalan, produksi kakao yang tinggi menjadikan Indonesia sebagai salah satu produsen dan eksportir biji kakao terbesar di dunia (Anggita dkk, 2015).

Biji kakao termasuk hasil perkebunan yang diekspor dan sangat menguntungkan bagi Indonesia. Namun kualitas biji kakao yang diekspor oleh Indonesia dikenal rendah. Rendahnya mutu kakao Indonesia ini disebabkan oleh beberapa hal, antara lain biji kakao Indonesia jarang yang difermentasi terlebih dahulu, padahal mutu biji yang telah difermentasi lebih baik daripada yang belum difermentasi. Selain itu, kakao Indonesia juga mempunyai keunggulan yaitu mempunyai titik leleh tinggi, mengandung lemak kakao dan dapat menghasilkan bubuk kakao (Hatmi, 2012).

Menurut Dinas Perkebunan Provinsi Sulsel (2014), Kabupaten Luwu mempunyai jumlah luas areal 35.226 Ha dan produksi biji kakao terbesar sebanyak 27.159 ton biji kakao kering pada tahun 2014. Dengan jumlah petani sebanyak $30.935 \mathrm{KK}$, produktivitas mencapai $1.018 \mathrm{Kg} / \mathrm{Ha}$. Sedangkan kakao termasuk komoditi ekspor andalan Propinsi Sulawesi Selatan dengan persentase 14,3\% dari keseluruhan ekspor (BPS, 2015).

Menurut Widyotomo et al (2004), ukuran biji kakao yang memenuhi kriteria standar ekspor adalah AA, A dan B (101-110 biji per $100 \mathrm{~g}$ ). Secara umum biji kakao fermentasi dari daerah Belopa, Kab. Luwu memenuhi standar untuk diekspor. Biji dan pulp kakao mengalamipenurunan berat sampai $25 \%$ selama proses fermentasi sebagai akibat penguapan air (Nasution et al, 1985).

Ukuran biji kakao kering sangat dipengaruhi oleh jenis (klon) tanaman, kondisi lingkungan (curah hujan) selama perkembangan buah dan tindak agronomis pada tanaman. Menurut Mulato dkk (2004), makin besar ukuran biji maka semakin besar pula kadar airnya, begitupun dengan rendemen lemaknya (Hatmi, 2012).

Teknik sambung samping merupakan teknik perbanyakan tanaman secara vegetatif dengan menggabungkan bagian dari satu tanaman ke tanaman lain yang sejenis (satu famili) sehingga tumbuh menjadi satu tanaman dan mempunyai sifat yang sama dengan induknya (entrisnya). Hasil penelitian menunjukkan bahwa sambung samping dapat berproduksi pada umur $9-12$ bulan sesudah perlakuan (Firdaus, 2015). Sambung samping sebaiknya dilakukan pada awal musim hujan, agar tunas yang tumbuh dari sambungan dapat tumbuh dengan cepat. Keuntungan teknologi sambung samping tanaman kakao adalah lebih mudah pelaksanaannya, sehingga areal pertanaman kakao dapat direhabilitasi dalam waktu singkat, dan tanaman kakao lebih cepat berproduksi. Sementara batang atas belum berproduksi, hasil buah dari batang bawah masih dapat dipertahankan, batang bawah dapat berfungsi sebagai penaung sementara bagi batang atas yang sedang tumbuh (Firdaus, 2015).

\section{Metodologi}

Penelitian ini dilaksanakan di Desa Pussui, Kecamatan Luyo, Kab. Polewali Mandar, pada perkebunan Kakao Petani, yang dilaksankan pada tanggal 25 Maret - 29 Agustus 2020. Perlakuan yang diteliti yaitu teknik sambung samping yang memggunakan entris S1, S2, dan MCC, sedangkan sebagai sampel kontrol yaitu kakao lokal, bahan yang digunakan dalam penelitian ini diantaranya pupuk, pestisida, karung, terpal dan plastik, sedangkan peralatan yang digunakan yaitu parang, gerobak, gunting pemotong, dan timbangan.

Pengujian parameter dilakukan dengan 3 kali ulangan dan menggunakan analisi RAK (Rancangan Acak Kelompok) untuk mengetahui seberapa besar teknik sambung samping berpengaruh terhadap sifat fisik buah kakao

\section{Hasil}

Sifat fisik buah kakao diamati dengan mengukur panjang buah, diameter buah, dan berat buah kakao, yang diuji secara obyektif, dari data yang diperoleh kemudian dianalisis menggungan metode RAK dan Uji Anova, setelah itu menentukan seberapa besar teknologi sambung samping memberikan pengaruh terhadap sifat fisik buah kakao.

\subsection{Panjang Buah}

Panjang buah merupakan salah satu parameter yang diamati untuk melihat kualitas fisik dari buah kakao dengan tiga entris berbeda dan kakao lokal sebagai parameter kontrol, disajikan pada grafik 1 berikut.

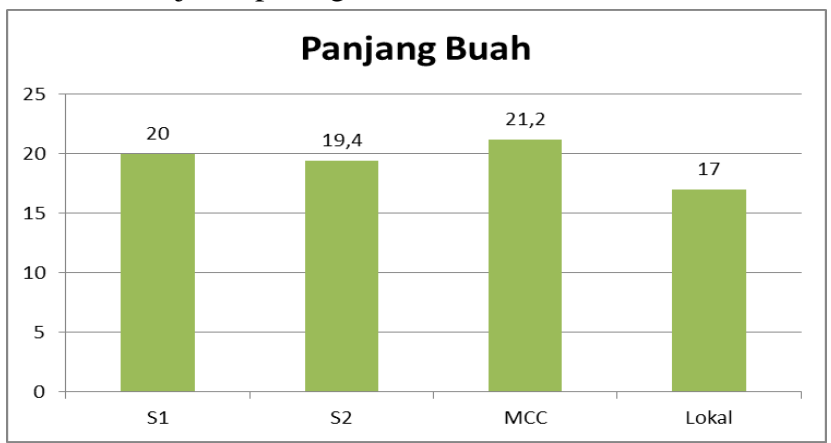

Grafik 1. Panjang Buah Kakao

Berdasarkan pengukuran terhadap berat buah yang dilakukan, diperoleh hasil bahwa berat buah mengalami peningkatan dengan pengaplikasian teknik sambung samping, dimana kakao lokal tanpa perlakuan berat buah yang dihasilkan sangat rendah yaitu hanya sepanjang $17 \mathrm{~cm}$, sedangkan untuk nilai panjang buah yang paling tinggi dengan menggunakan entris MCC. Berdasarkan uji anova yang dilakukan menunjukkan bahwa $\mathrm{P}<0.05$ yang menandakan bahwa pengapliaksian teknik sambung 
samping dengan entris yang berbeda berpengaruh nyata terhadap sifat panjang buah yang dihasilkan sesuai dengan pendapat (Retno, 2018) bahwa faktor genetik dari tanaman kakao sangat berperngaruh terhadap ukuran dari buah kakao yang dihasilkan.

\subsection{Berat Buah}

Berat buah merupakan salah satu parameter yang diamati untuk menguji kualitas fisik dari buah kakao. Berat buah sebagai salah satu indikator besar atau kecilnya buah yang dihasilkan setelah mengaplikasikan teknik sambung samping pada tanaman kakao.

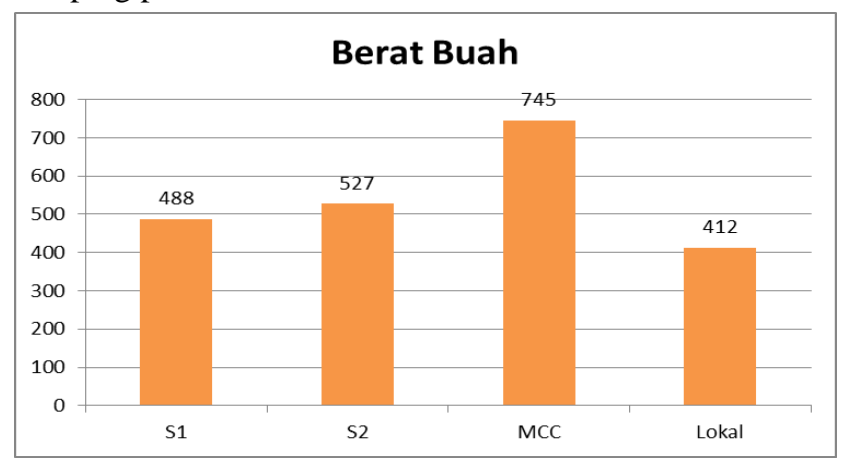

Gambar 2. Berat Buah Kakao

Berdasarkan uji berat buah yang dilakukan data menunjukkan bahwa terjadi peningkatan berat buah kakao setelah diberikan perlakuan sambung samping, dimana jenis kakao lokal tanpa perlakuan yaitu 412 gr, setelah diberikan teknologi sambung samping dengan entris yang berbeda diperoleh nilai berat tertinggi yaitu 745 gr pada entris MCC dan terendah pada entris S1 dengan nilai 488. Berdasarkan uji anova, diperoleh $(\mathrm{P}<0.05)$, yang menunjukkan bahwa teknik sambung samping berpengaruh nyata terhadap berat buah kakao.

\subsection{Diameter Buah}

Diameter buah merupakan ukuran lebar dari buah kakao, yang diukur melingkar pada bagian buah, yang diukur dengan menggunakan meteran, diameter buah merupakan salah satu parameter untuk mengamati ukuran buah kakao secara visual. Diameter buah dari masing-masing kakao, disajikan pada grafik 3 berikut.

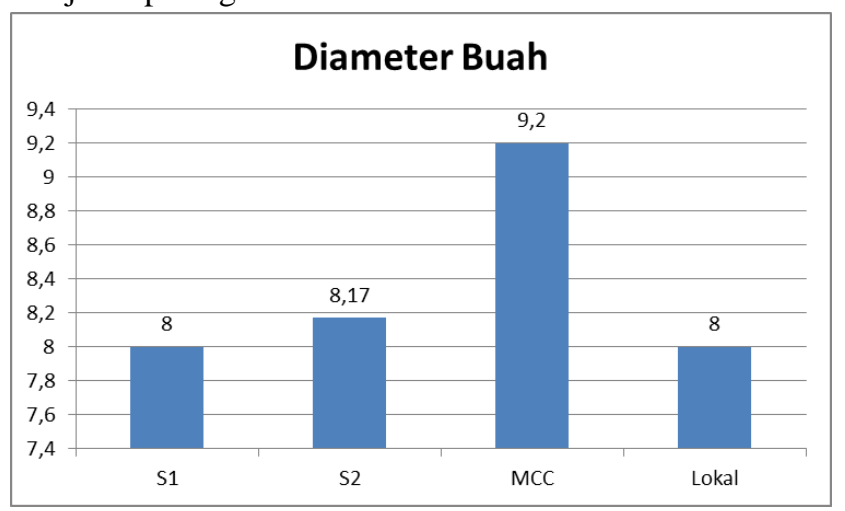

\section{Gambar 3. Grafik Diameter Buah}

Berdasarkan pengamatan yang telah dilakukan diperoleh data bahwa diameter buah kakao dipengaruhi oleh penggunaan entris pada saat pengaplikasian teknologi sambung samping. Buah dengan diamaeter paling besar yaitu menggunakan entris MCC dengan nilai 9,2 cm. Terjadi perubahan diameter dari buah kakao lokal tanpa sambung samping dengan kakao sambung samping dengan entris S2 maupun MCC.

Berdasarkan analisis duncan yang telah dilakukan menunjukkan bahwa ada perbedaan antara setiap perlakuan yang deberikan.

\section{Kesimpulan}

Berdasarkan penelitian yang dilakukan terhadap sifat fisik buah kakao yaitu Panjang buah, Berat Buah dan Diameter buah yang diapliaksikan teknik sambung samping menggunakan jenis klon yng berbeda - beda dapat disimpulkan bahwa teknologi peremajaan tanaman yaitu sambung samping menggunakan entris MCC sangat berpengaruh, dari klon Lokal sebagai sampel kontrol terjadi peningkatan yang signifkan dari ketiga parameter uji, sedangkan untuk entris S-1 dan S-2 hasil yang diperoleh sama.

\section{Ucapan Terima Kasih}

Ucapan terima kasih penulis sampaikan kepada DRPM Kemristekdikti atas pendanaan Tahun 2020 melalui Program Hibah Penelitian Dosen Pemula, dan juga kepada seluruh anggota tim kerja, dosen teman sejawat Fakultas ilmu Pertanian Unasman, LPPM Unasman yang telah membantu selama kegiatan penelitian

\section{Daftar Pustaka}

Anggita Tresliyana, Anna Fariyanti, dan Amzul Rifin (2015) Balai Besar Pengkajian dan Pengembangan Teknologi Pertanian, Badan Litbang.Departemen Agribisnis, Fakultas Ekonomi dan Manajemen, Institut Pertanian

BPS Prov. SulSel. (2015). Statistik Daerah Prov. SulSel 2015. http://sulsel.bps.go.id website/pdf_publi kasi/Statistik- DaerahProvinsi-.

Firdaus, 2015. Teknologi Sambung Samping dapat Meningkatkan Produktivitas Kakao Petani di Provinsi Aceh. http://nad.litbang.pertanian.go.id. Diakses pada tanggal 6 April 2015: Makassar.

Hatmi, R. U., \& Rustijarno, S. (2012). Teknologi Pengolahan Biji Kakao Menuju SNI Biji Kakao 01-2323-2008. BPTP Yogyakarta

Mulato, S., Widyotomo, Misnawi, Sanali, dan E. Suharyanto. (2004). Petunjuk Teknis Pengolahan Produk Primer dan Sekunder Kakao. Bagian ProyekPenelitian dan Pengembangan Kopi dan Kakao, Pusat Penelitian Kopi dan Kakao Indonesia. 
Nasution, MZ, Tjiptadi W dan Laksmi BS. (1985). Pengolahan Cokelat. Bogor: Agroindustri Press.

Organization, I. C. (2017). Daya Saing Kakao Indonesia Di Pasar Internasional 1995-2015, International Cocoa Organization.

Perkebunan, D. J. (2016). Statistik Perkebunan Indonesia Kakao 20152017. Jakarta, Sekretariat Direktorat Jenderal Perkebunan.

Puspita, R., et al. (2015). "Pengaruh Produksi Kakao Domestik, Harga Kakao Internasional, Dan Nilai Tukar Terhadap Ekspor Kakao Indonesia Ke Amerika Serikat (Studi pada Ekspor Kakao Periode Tahun 2010-2013)" Jurnal Administrasi Bisnis 27.

Retno U. H, Makhmudun A. dan Anggro C. S. 2018. Analisis Sebaran Tipe dan Performa Mutu Fisik Kakao Pada Tiga Rentang Elevasi.Balai Pengkajian Teknologi Pertanian Yogyakarta. Departemen Teknolgi Industri Pertanian, Fakultas Teknologi Pertanian, Universitas Gadjah Mada.

Widyotomo, S., Mulato, S., \& Handaka. (2004). Mengenal Lebih Dalam Teknologi Pengolahan Biji Kakao. Warta Litbang Pertanian, 26, 5-6. 